\title{
Probing ZnAPO-34 Self-Assembly Using Simultaneous Multiple in Situ Techniques
}

\author{
Andrew M. Beale, ${ }^{*,+}$ Matthew G. O’Brien, ${ }^{\dagger}$ Marta Kasunič, ${ }^{\ddagger}$ Amalija Golobič, ${ }^{\ddagger}$ Manuel Sanchez-Sanchez, ${ }^{\S}$ \\ Alan J. W. Lobo," Dewi W. Lewis," David S. Wragg, ${ }^{\perp}$ Sergey Nikitenko," Wim Bras, ${ }^{\#}$ and \\ Bert M. Weckhuysen ${ }^{*,+}$
${ }^{\dagger}$ Inorganic Chemistry and Catalysis, Debye Institute for NanoMaterials Science, Utrecht University, Sorbonnelaan 16, 3584 CA Utrecht, The Netherlands
${ }^{\ddagger}$ Faculty of Chemistry and Chemical Technology, University of Ljubljana, Aškerčeva 5, 1000 Ljubljana, Slovenia
${ }^{\S}$ CSIC, Instituto de Catalisis y Petroleoquimica, E-28049 Madrid, Spain
"Department of Chemistry, University College London, 20 Gordon Street, London WC1H 0AJ, United Kingdom
${ }^{\perp}$ inGAP Centre for research based innovation, University of Oslo, POB 1033 Blindern, N-0315 Oslo, Norway
\#DUBBLE@ESRF, BP 220, F-38043 Grenoble Cedex, France

Supporting Information

ABSTRACT: The hydrothermal crystallization of ZnAPO-34 (CHA) molecular sieves has been studied for the first time using a combined in situ four technique setup utilizing SAXS/WAXS/XAFS/Raman to follow the various steps that occur during the complex transformation process of an amorphous precursor gel into a crystalline microporous material. These data are also supported by a detailed characterization of both the precursor gel (using Raman, NMR, XAFS, and TEM) and the final crystalline material (NMR, XRD, XAFS, TEM, and energy minimization calculations). Thus, all components during the various stages of reaction have been studied allowing for fundamental insight from the atomic/molecular level up to the bulk scale. On the basis of this multitechnique approach, the following observations are made: (i) The initial formation of a heterogeneous gel containing predominantly separate $\mathrm{Al}-\mathrm{O}-\mathrm{P}$ and $\mathrm{Zn}-\mathrm{O}-\mathrm{P}$ containing species as well as the presence of particles with a broad size distribution were noted.

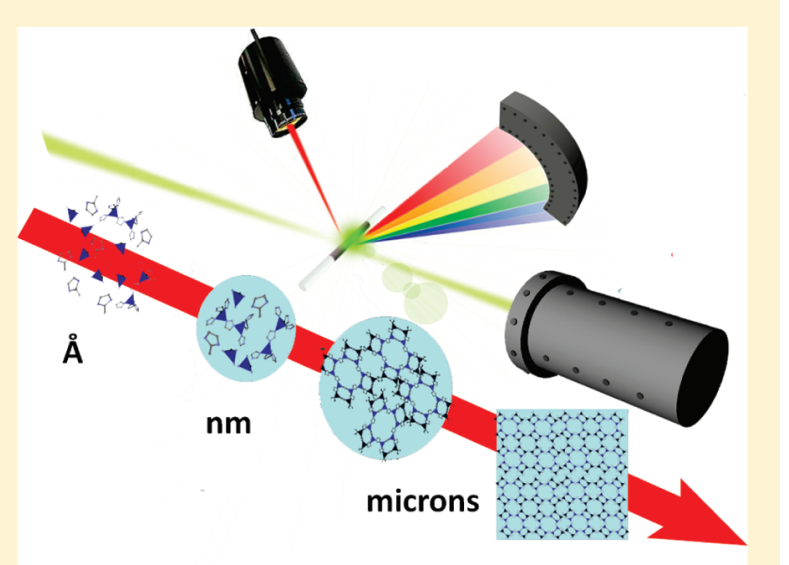

(ii) During sample heating, the SAXS data reveal a second population (14-16 nm) at the onset of crystallization, which were also accompanied by changes in both the $\mathrm{ZnO}_{3}-\mathrm{O}-\mathrm{O}_{3} \mathrm{P}$ environment (XAFS) and the template conformer state (Raman). (iii) Before crystallization, $\mathrm{Zn}^{2+}$ species appear heterogeneously distributed throughout the sample, but in the final crystalline $\mathrm{CHA}$ phase $\mathrm{Zn}{ }^{2+}$, it is much more homogeneously distributed. One template molecule is found per CHA cage. (iv) $\mathrm{Zn}^{2+}$ is found to promote nano particle growth and that results in the production of increasing amounts of crystalline material. (v) The structure-directing effect of $\mathrm{Zn}^{2+}$ ions leading to CHA formation is most likely initiated via an electrostatic interaction between $\mathrm{Zn}^{2+}$ in a $\mathrm{Zn}-\mathrm{O}-\mathrm{P}-\mathrm{O}-\mathrm{Al}-$ $\mathrm{O}-\mathrm{P}$ matrix and the TEA template.

\section{INTRODUCTION}

The crystallization mechanisms of microporous materials, such as zeolites and aluminophosphates, have held a certain fascination for researchers for a number of decades. It is hoped ultimately that a mastery of these processes could lead to better control over the synthesis outcome and to the rational design of such industrially important materials. Traditionally microporous materials are crystallized under hydrothermal conditions either from clear solutions or from gels. Either way, insight into the formation mechanism(s) is best obtained when performing timeresolved in situ studies. A great deal of literature already exists on the subject, and many conclusions and concepts have been proposed, most of which have been summarized recently in a few excellent reviews. ${ }^{1-5}$ The majority of this research effort has focused on the study of one or two industrially important zeolite systems (silicalite/ZSM-5 (MFI) and zeolite A(LTA)) from clear (dilute) solutions and has led to some important observations being made and an improved understanding of zeolite selfassembly. ${ }^{8-8}$ However, the question remains as to whether the observations made in these studies are more widely applicable to

\footnotetext{
Received: January 3, 2011

Revised: February 13, 2011

Published: March 07, 2011
} 
microporous materials in general under hydrothermal conditions, particularly because many zeolites and practically all microporous aluminophosphates are crystallized from thick gels. Under nonhydrothermal conditions, this question becomes even more pertinent. $^{9-12}$

To date, a number of in situ crystallization studies probing microporous aluminophosphate synthesis exist, the majority of which focus on (Co)APO-5 (AFI structure). ${ }^{13-33}$ These studies utilize mostly scattering methods for probing the onset of crystallization, although many also employ spectroscopic techniques allowing for atomic/molecular insight into the self-assembly process. Studies in which a combination of techniques have been employed, in particular those employing both spectroscopic and scattering methods, have proved particularly revealing. ${ }^{16,22,28}$ From those studies, it would appear that the crystallization of microporous aluminophosphates can be rationalized into four general steps: (1) the initial formation of a reactant gel, comprising $(\mathrm{Me}) \mathrm{AlO}_{3 / 5}-\mathrm{O}-\mathrm{PO}_{3}$ type nanometer-sized primary species, (2) the growth of such species into secondary larger macromolecularly disordered aggregates containing interdispersed template cations, (3) the onset of crystallization, and (4) crystallite growth. In addition, it has been shown that incorporation of transition metal ions into the framework occurs predominantly as the crystalline material forms. ${ }^{20,28,29}$ Despite such revealing studies, a number of pertinent scientific questions remain. These include, for example, whether the above mechanism is applicable to the formation of other aluminophosphate structures and why/how some of the framework components direct the formation of a particular microporous structure. In particular, a detailed examination of the role and behavior of the template molecule as well as the examination of important template-framework interactions is likely to be key to understanding how microporosity is introduced into aluminophosphate frameworks. ${ }^{24,34}$

In this work, we performed a detailed examination of the crystallization of $\mathrm{ZnAPO}-34$ with the $\mathrm{CHA}$ structure to gain more insight into microporous material crystallization. ${ }^{35}$ The formation process has been studied using a unique bespoke setup in which the X-ray-based techniques XAFS, small-angle X-ray scattering (SAXS), and wide-angle X-ray scattering (WAXS) have been combined with Raman spectroscopy to obtain a more detailed insight into the formation of the $\mathrm{Zn}^{2+}$ substituted form of the CHA framework. ${ }^{16,22,25,36}$ Importantly, this combination of techniques allows us to examine the interplay between the $\mathrm{Zn}^{2+}$ species, the template molecule, the initial gel species, and the final crystalline material providing for more detailed insight into the essential steps leading to microporous aluminophosphate formation. In addition, these studies and the conclusions drawn from them were also supplemented by both pre- and postsynthesis analysis of the material.

\section{EXPERIMENTAL SECTION}

Materials Synthesis. The following chemicals and synthesis methods were used for the preparation of $\mathrm{ZnAPO}-34$ according to synthesis procedures previously described. ${ }^{24}$

Gels were prepared with the following molar ratios:

$$
\begin{gathered}
1.5 \mathrm{H}_{3} \mathrm{PO}_{4}: 1-x \mathrm{Al}(\mathrm{OH})_{3} \cdot y \mathrm{H}_{2} \mathrm{O}: x\left(\mathrm{CH}_{3} \mathrm{COO}\right)_{2} \mathrm{Zn} \cdot 2 \mathrm{H}_{2} \mathrm{O}: \\
0.8 \mathrm{TEAOH}: 26 \mathrm{H}_{2} \mathrm{O}
\end{gathered}
$$

where $x$ is the molar amount of $\mathrm{Zn}^{2+}$ used and which was varied between 0.1 and 0.3 . In a typical experiment, $3.38 \mathrm{~g}$ of $\mathrm{H}_{3} \mathrm{PO}_{4}$
(Sigma-Aldrich, $85 \% \mathrm{wt}$ ) and $4.44 \mathrm{~g}$ of doubly distilled water were mixed in a Teflon beaker with mechanical stirring. The desired amount of $\left(\mathrm{CH}_{3} \mathrm{COO}\right)_{2} \mathrm{Zn} \cdot 2 \mathrm{H}_{2} \mathrm{O}$ (Sigma-Aldrich, $\geq 98 \%$ ) was then added. Upon dissolution, the corresponding amount of $\mathrm{Al}\left(\mathrm{OH}_{3}\right) \cdot y \mathrm{H}_{2} \mathrm{O}$ (Sigma-Aldrich, $\geq 98 \%$ ) was added slowly to the solution and then stirred until a homogeneous gel had been formed (ca. $10 \mathrm{~min}$ ). Finally, $6.56 \mathrm{~g}$ of TEAOH (tetraethylammonium hydroxide solution) (Sigma-Aldrich, 35\% wt) was added dropwise to the gel. The solution was then stirred mechanically until a viscous homogeneous gel had again formed (ca. $15 \mathrm{~min}$ ). The $\mathrm{pH}$ values of the solutions at various stages of mixing were $\leq 1\left(\mathrm{H}_{3} \mathrm{PO}_{4}, \mathrm{H}_{2} \mathrm{O},\left(\mathrm{CH}_{3} \mathrm{COO}\right)_{2} \mathrm{Zn} \cdot 2 \mathrm{H}_{2} \mathrm{O}\right), 2-3$ $\left(\mathrm{H}_{3} \mathrm{PO}_{4}, \mathrm{H}_{2} \mathrm{O},\left(\mathrm{CH}_{3} \mathrm{COO}\right)_{2} \mathrm{Zn} \cdot 2 \mathrm{H}_{2} \mathrm{O}, \mathrm{Al}(\mathrm{OH})_{3} \cdot y \mathrm{H}_{2} \mathrm{O}\right)$, and 3-4 $\left(\mathrm{H}_{3} \mathrm{PO}_{4}, \mathrm{H}_{2} \mathrm{O},\left(\mathrm{CH}_{3} \mathrm{COO}\right)_{2} \mathrm{Zn} \cdot 2 \mathrm{H}_{2} \mathrm{O}, \mathrm{Al}(\mathrm{OH})_{3} \cdot y \mathrm{H}_{2} \mathrm{O}\right.$, TEAOH).

Combined in Situ SAXS/WAXS/XAFS/Raman Data Collection. Data collection using SAXS/WAXS/XAFS/Raman was carried out on beamline BM26A at the ESRF (Grenoble, France) using a $\mathrm{Si}(111)$ double crystal fast scanning monochromator. A photograph of the setup is given in Figure S7 (Supporting Information). Mirror focusing was used to remove the higher harmonics. An ion chamber (for $I_{\mathrm{o}}$ ) and photodiode $\left(I_{\mathrm{t}}\right)$ located in the SAXS vacuum camera tube were used for recording XAFS data, whereas SAXS/WAXS data were recorded simultaneously using a 1D quadrant gas-filled detector positioned at a distance of $1.8 \mathrm{~m}$ from the sample (SAXS) and position sensitive curved gaseous INEL CPS 590 detector (WAXS). ${ }^{22}$ WAXS and EXAFS data acquisition was controlled using the sequence mode of the EXAFS program developed at Daresbury laboratory. SAXS data were collected on a separate computer using the locally developed SAXS GUI program. A total cycle time of 6 min was employed to collect these data (3 min for XAS from 9.465-10.30 $\mathrm{keV}$ and $3 \mathrm{~min}$ for SAXS/WAXS at a wavelength of $1.3098 \AA$ ), which includes a $10 \mathrm{~s}$ dead time to move the monochromator back to the start position.

Two different cells were used for the in situ measurements. In the first type, type I, a sealed capillary was loaded with the reactant solution/gel and sealed at one end with epoxy resin. The sample was then pressurized with compressed air and mounted on a goniometer to align the sample with the incoming beam. ${ }^{37}$ Heating was then achieved using hot air blower-type minisensor heaters (see Figure S7). However, because of poor XAFS data quality due in part to sample movement, combined XAFS/XRD experiments were then repeated using the previously described cell/heating block system (type II). ${ }^{20}$ In both cases, a ramp rate of $5^{\circ} \mathrm{C} / \mathrm{min}$ was employed to heat the sample to a temperature of $70{ }^{\circ} \mathrm{C}$ (which was then held) from an initial temperature of $30{ }^{\circ} \mathrm{C}$. For both types of experiment, a beam size of $150 \mu \mathrm{m} \times$ $3 \mathrm{~mm}(h \times w)$ was used and positioned in the lower part of the cell aperture.

Calibration of the SAXS detector was performed using both a silver behenate and wet rat-tail collagen reference samples. ${ }^{38}$ Although data were collected over a $q$-range of $0.3<k<2 \mathrm{~nm}^{-1}$, due to the limitations imposed by the sample and the cell, analysis could only be performed over the range $0.3<k<$ $0.9 \mathrm{~nm}^{-1}$. However, previous measurements on these samples demonstrated that it was still possible to identify global changes that occurred in the amorphous gel before the onset of crystallization.

WAXS data collection was performed using a curved INEL detector. Calibration was performed using a NIST silicon standard in which the $d$-spacing for a number of reflections (e.g., 111, 220, 
311 , etc.) is well-known and was recorded, and the differences between the $2 \theta$ values observed versus the $2 \theta$ values expected was approximated using a linear function. Peak broadening effects were empirically determined using a crystalline sample in which the crystallite size has been determined using transmission electron microscopy (TEM). This value can then be incorporated into a particle size estimation using the well-known Scherrer equation. In this case, we compared four Bragg peaks from a fully crystallized AlPO-5 sample, which did not appear to suffer significantly from strain or stacking faults, to estimate approximately the degree of "instrument broadening". ${ }^{35}$ Peak profiling was performed using a pseudo-Voigt function and the GRAMS/AI spectroscopy software suite.

XAFS data were processed using bespoke programmes for converting the raw data files to energy versus absorption coefficient, Athena, to obtain the normalized XANES part of the spectra (normalized to give an edge jump of 1) and for pre- and postedge background subtraction and DLEXCURV to perform a least-squares iterative fitting of the EXAFS data. ${ }^{39,40}$ EXAFS refinements were performed on data recorded using the in situ hydrothermal (type II cell). The data were $\mathrm{k}^{3}$-weighted and plotted over a $k$-range of $3.4-10 \AA^{-1}$. Refinements of the EXAFS data were performed considering both single scattering (first shell oxygen $(\mathrm{O})$ neighbors) and where possible/appropriate multiple scattering paths for high shell fitting $(\mathrm{P})$. A best fit of the data (in $\mathrm{k}$-space) was determined by minimizing the EXAFS $R$ factor (a meaningful indication of the quality of fit of the EXAFS data as a percentage). Because these data were obtained in timeresolved mode, typical $R$-factors were between $28 \%$ and $35 \%$.

Raman spectra were recorded with a $532 \mathrm{~nm}$ laser operating at $35 \mathrm{~mW}$ and a Holoprobe Kaiser Optical spectrometer equipped with a holographic notch filter and CCD camera. The Raman laser beam was focused onto the same part of the sample as the $\mathrm{X}$-rays. Data were collected for $30 \mathrm{~s}$ every $1 \mathrm{~min}$ during both heat ramping and dwell stages. All data were recorded using the Holograms software suite, whereas analysis and Raman band profiling were performed using the GRAMS/AI spectroscopy software package. Elemental sulfur was used to verify the calibration and to maximize the intensity of the signal. Data were collected over a range of $300-4300 \mathrm{~cm}^{-1}$. The GRAMS/AI software suite was used to first perform a multipoint manual baseline subtraction over the entire spectra; however, peak profiling, concentrating on the region (shown in that the intensity of the $v\left(\mathrm{C}_{4} \mathrm{~N}\right)$ bands at $662(\mathrm{tg} \cdot \mathrm{tg})$ and $672 \mathrm{~cm}^{-1}(\mathrm{tt} \cdot \mathrm{tt})$ gives a quantitative indication of the amount of TEAOH template in each orientation), was performed using the in-built Gaussian fitting routines in the software to accurately measure the band height of each template conformer state. ${ }^{41}$ In all cases, the full width at halfmaximum (fwhm) was constrained to accurately simulate the peak shapes and positions. The ratios of the intensities of these two Raman bands were then compared to assess the amount of each template conformation present in the gel.

NMR Data Collection. ${ }^{31} \mathrm{P}$ and ${ }^{27} \mathrm{Al}$ magic-angle spinning nuclear magnetic resonance (MAS NMR) spectra were recorded using a Bruker AV-400 spectrometer (9.4 T) at 161.9 and 104.2 $\mathrm{MHz}$, respectively, under ${ }^{1} \mathrm{H}$ decoupling. Spinning rates of $5 \mathrm{kHz}$ for gel-like samples and $14 \mathrm{kHz}$ for dried samples were used, with a pulse length of $\pi / 2$ and pulse delays of $60 \mathrm{~s}$ applied for ${ }^{31} \mathrm{P}$ NMR spectra, whereas the same spinning rates of $5 \mathrm{kHz}$, pulses of $\pi / 12$, and pulse delay of $2 \mathrm{~s}$ were used for the acquisition of ${ }^{27} \mathrm{Al}$ NMR spectra. The ${ }^{31} \mathrm{P}$ and ${ }^{27} \mathrm{Al}$ chemical shifts were referenced, respectively, against $\mathrm{H}_{3} \mathrm{PO}_{4}$ and $\mathrm{Al}\left(\mathrm{H}_{2} \mathrm{O}\right)_{6}{ }^{3+}$ aqueous solutions, both taken as 0 ppm.

TEM Data Collection. Particle morphology and size were determined with a Tecnai FEI XL 30SFEG scanning electron microscope (SEM) at $15 \mathrm{kV}$ and with a Tecnai 20 transmission electron microscope operated at $200 \mathrm{kV}$. The samples were loaded in dry form onto electron tomography (ET) grids. As well as imaging, elemental analysis and electron diffraction measurements were also performed.

XRD Data Collection. Diffraction data were collected on 20\% and $30 \% \mathrm{Zn}^{2+}$ containing $\mathrm{ZnAPO}-34$ samples in flat plate mode on a PANalytical X'Pert PRO MPD diffractometer with BraggBrentano geometry and $\mathrm{Cu} \mathrm{K}_{\alpha 1}$ radiation. Data were collected over a $2 \theta$ range of $5-80^{\circ}$ using a step size of $0.034^{\circ}$ with a total integration time of $100 \mathrm{~s}$ per step (the full range of the 128 channel linear RTMS detector was used, so that each channel integrated the intensity for about $0.8 \mathrm{~s}$ at each step). Rietveld refinement of the data was then carried out using the TOPAS Academic software. ${ }^{42}$ As a starting structural model, literature data for ZnAPO-34 with $20 \% \mathrm{Zn}$ crystallizing in a rhombohedral unit cell $\left(a=9.371 \AA, \alpha=\beta=\gamma=94.87^{\circ}\right)$ in space group $R-3$ (no. 148) were used. This model contains one TEA cation per unit cell that is in agreement with theoretical calculations (see the following section), but it also includes six water molecules per unit cell. For the $30 \% \mathrm{Zn}$ sample, the occupancy of the common $\mathrm{Zn}-\mathrm{Al}$ site was adjusted appropriately. ${ }^{43}$ No structural parameters (unit cell parameters, atomic coordinates, and isotropic displacement parameters) were refined due to low crystallinity of the product. For both data sets, a Thompson-Cox-Hastings pseudo-Voigt function was used to profile the peak shapes. ${ }^{44}$ An eighth-order Chebyshev polynomial was used as a background description. Also included in the refinement were the scale factor, zero error parameter, and a fourth-order spherical harmonics for a description of preferential orientation; thus a maximum of 21 parameters were refined.

Theoretical Calculations. The aim of the Molecular Mechanics (MM) calculations was to find the most stabilized conformation of the tetraethylammonium (TEA) ion in the CHA and AFI structures. For this purpose, we used the Zeolites By Evolutionary De Novo Design program (ZEBEDDE), which has since been modified to perform docking and simulated annealing calculations at $0 \mathrm{~K}^{45-47}$ A single TEA molecule is randomly placed within the CHA framework, and the interaction energy is calculated using the PCFF forcefield. ${ }^{48}$ If the energy is below a threshold, the structure is accepted and output for further optimization by ZEBEDDE where the molecule is translated and rotated into a more favorable position. 50 docked structures were generated for each framework/TEA conformation combination, and the interaction energy was averaged. When adding a second TEA molecule to the CHA cage, the best (most negative) interaction energy of the 50 single docked structures was taken and a second TEA added manually, positioning it slightly above the initial one. The simulated annealing routines in ZEBEDDE were then used to optimize the positions of both TEA molecules. Five annealed structures were generated from the initial starting configuration, and the interaction energy was averaged. The frameworks for CHA and AFI were both optimized with GULP using the Gale and Henson potentials. ${ }^{49,50}$ The framework and conformation of the TEA molecule are then fixed for the calculations.

\section{RESULTS}

The results from the study are presented in three parts: a brief summary of the initial characterization of the synthesis gel, a 


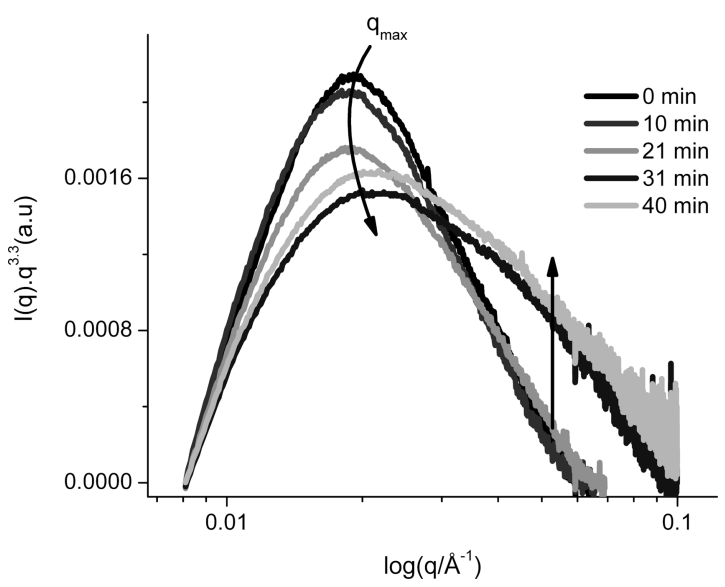

Figure 1. SAXS data recorded during the in situ combined SAXS/ WAXS/XAFS/Raman measurements on heating a ZnAPO gel $(30 \%$ $\mathrm{Zn}^{2+}$ ) at $70^{\circ} \mathrm{C}$ as a function of time. The arrow labeled $q_{\max }$ illustrates the shift of the centroid position of the scattering signal with time, while the upward arrow highlights the appearance of a second feature in the data.

detailed analysis of the combined in situ study data, and finally postsynthesis characterization studies. Pre- and post-synthesis characterization were performed on gels and samples made from these gels with the following chemical composition: of $1.5 \mathrm{H}_{3} \mathrm{PO}_{4}: 0.8 \mathrm{Al}-$ $(\mathrm{OH})_{3} \cdot y \mathrm{H}_{2} \mathrm{O}: 0.2\left(\mathrm{CH}_{3} \mathrm{COO}\right)_{2} \mathrm{Zn} \cdot 2 \mathrm{H}_{2} \mathrm{O}: 0.8 \mathrm{TEAOH}: 26 \mathrm{H}_{2} \mathrm{O}$, while the in situ data were recorded on samples with a chemical composition of $1.5 \mathrm{H}_{3} \mathrm{PO}_{4}: 0.7 \mathrm{Al}(\mathrm{OH})_{3} \cdot y \mathrm{H}_{2} \mathrm{O}: 0.3\left(\mathrm{CH}_{3} \mathrm{CO}\right.$ $\mathrm{O})_{2} \mathrm{Zn} \cdot 2 \mathrm{H}_{2} \mathrm{O}: 0.8 \mathrm{TEAOH}: 26 \mathrm{H}_{2} \mathrm{O}$. The use of a higher concentration was chosen for the in situ studies to maximize signal response (XAFS, Raman, XRD, etc.) but was not used for ex situ studies to minimize the risk of a secondary zinc-rich phase, which forms occasionally.

Characterization of the Initial Gel. Spectroscopic data and the corresponding interpretation from the starting gel can be found in the Supporting Information. From these studies, it could be concluded that the initial gel is highly heterogeneous, comprising $\mathrm{Al}-\mathrm{O}-\mathrm{P} / \mathrm{Zn}-\mathrm{O}-\mathrm{P}$ and probably $\mathrm{Zn}-\mathrm{O}-\mathrm{P}-\mathrm{O}-$ $\mathrm{Al}$ species ranging in complexity from simple binary cationic complexes in solution to large polymeric gel species. TEM data recorded on a filtered and air-dried gel are shown in Figure S6 and reveal a series of spherical, irregularly shaped aggregates with a size range between 10 and $60 \mathrm{~nm}$, which electron diffraction measurements reveal to be diffraction amorphous.

In Situ Crystallization Studies. SAXS Data. Figure 1 shows the time-resolved $I(q) \cdot q_{\mathrm{n}}$ versus $\log (q)$ scattering profiles measured as a function of time before and during the onset of ZnAPO-34 crystallization. As with previous measurements performed on aluminophosphate gels, the SAXS intensity $I(q)$ closely follows a power-law decay $k^{-n}$ with $n$ close to -3 and is indicative of particles present being poorly/irregularly structured (i.e., not compact with sharp interfaces) ${ }^{25,27}$ After removing the leading $q^{-3}$ decay of the $I(q) \cdot q^{3}$ dependence, it is possible to observe a difference between the scattering profiles. The plots exhibit a broad maximum (defined as $q_{\max }$ ), which can be fitted with Gaussian function(s) and approximated to the inverse of the typical size of possible gel aggregates/precursors that form during $\mathrm{ZnAPO}-34$ crystallization. This initial value for $q_{\max }\left(0.019 \AA^{-1}\right)$ would correspond to a nominal aggregate size of ca. $37 \mathrm{~nm}$, which is within the range of aggregate sizes observed in the TEM data.
On commencing heating, $q_{\max }$ first increases very slightly, while the overall SAXS signal at and around $q_{\max }$ begins to decrease. After $31 \mathrm{~min}$, a second component appears in the SAXS data, which can be approximated also with a Gaussian function yielding a second maximum around $0.038 \AA^{-1}$ (ca. $14 \mathrm{~nm}$ ). Further heating (to $40 \mathrm{~min}$ ) sees only small changes in both components before the SAXS signal disappears from the detector.

WAXS Data. The three-dimensional stack plot in Figure 2a contains data from a selected $2 \theta$ region $\left(15-40^{\circ}\right)$ of the WAXS pattern collected as a function of temperature during the transformation of the precursor gel into $\mathrm{ZnAPO}-34{ }^{51}$ The onset of crystallization is characterized by a decrease in the amorphous background $\left(10-30^{\circ}\right)$ followed by the first appearance of Bragg peaks at $17.7^{\circ} 2 \theta(-120 /-210$ reflection(s) of ZnAPO-34) in the pattern, ca. $15 \mathrm{~min}$ into the reaction. Additional peaks at $26.13^{\circ}(-311)$ and $26.57^{\circ}(130 / 310)$ after ca. $40 \mathrm{~min}$ and $21.42^{\circ}$ (211), $22.13^{\circ}(-220)$ after ca. $50 \mathrm{~min}$ appeared later. All reflections are consistent with the presence of $\mathrm{ZnAPO}-34(R \overline{3}$ space group) and indicate that this phase forms exclusively and directly from the amorphous precursor gel without the occurrence of any intermediate crystalline phase. The intensity of the Bragg peaks increases for ca. $140 \mathrm{~min}$ (resulting in the typical S-shaped crystallization curve shown in Figure $2 b$ ), after which no further change is observed. An analysis of the data (Table S1) performed on three distinct reflections reveals similar values for the growth parameters, indicating isotropic crystal growth. A Scherrer analysis of the $-120 /-210$ reflection reveals an initial $\mathrm{ZnA}$ PO-34 particle size of ca. $12 \mathrm{~nm}$.

XAFS Data. Figure 3a contains a 2D overlay plot from the normalized Zn K-edge XANES spectra recorded during the data acquisition. At first glance, comparatively little seems to occur during the crystallization process, but a feature close to $9.677 \mathrm{keV}$ can be seen to evolve as a function of reaction time. Because of the high noise level, it is difficult to determine when this feature becomes first discernible. However, the growth in its intensity appears consistent with increasing amounts of crystalline material, and it is therefore likely to be attributable to multiple scattering events. ${ }^{52}$ Such a change would also be consistent with the incorporation of $\mathrm{Zn}^{2+}$ ions into framework positions within the ZnAPO-34 lattice.

Clearly the data presented in Figure 3a do not readily lend themselves to EXAFS analysis. Therefore, a separate XAFS/ WAXS experiment was performed using a hydrothermal reactor cell to obtain analyzable EXAFS data. The data from this separate combined experiment are shown in Supporting Information Figure S8, and a 2D overlay plot of the FT data ( $\mathrm{k}^{3}$ weighted) is given in Figure 3b. As can be seen from a visual inspection of the data in this figure, very few changes appear to take place within the first coordination environment of $\mathrm{Zn}(\mathrm{Zn}-\mathrm{O}$ contribution at ca. $1.95 \AA$ ) during reaction, although there are more significant changes in the high coordination environment $(\mathrm{Zn}-\mathrm{P}$ contributions between 2.5 and $3.5 \AA$ ). Such changes suggest that the immediate coordination environment around $\mathrm{Zn}$ does not change during reaction but that the second/higher coordination sphere does. Least squares fitting of the EXAFS data (Table 1) supports these observations, the first shell oxygen coordination number at the beginning and end of the experiment refining to ca. 4 , at $1.93 \AA$, while the second coordination environment could be modeled (when including multiple scattering contributions) at the beginning with $\mathrm{Zn}-\mathrm{P}$ scattering contribution(s) at 3.20 (2) and 3.55 (2) $\AA$, while at the conclusion of the experiment higher shell signals are found at a shorter distance. We suppose that the 


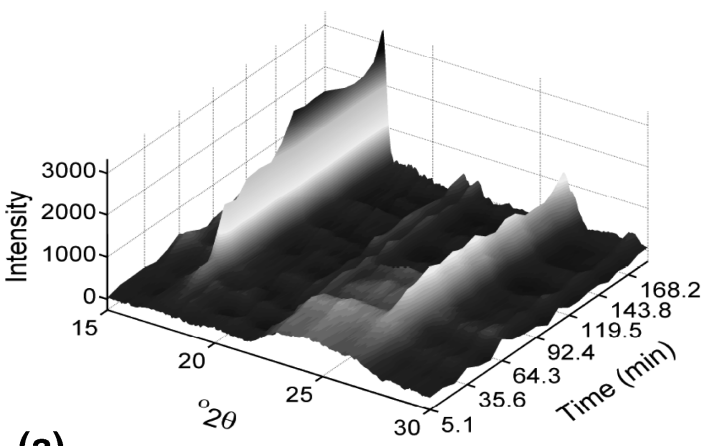

(a)

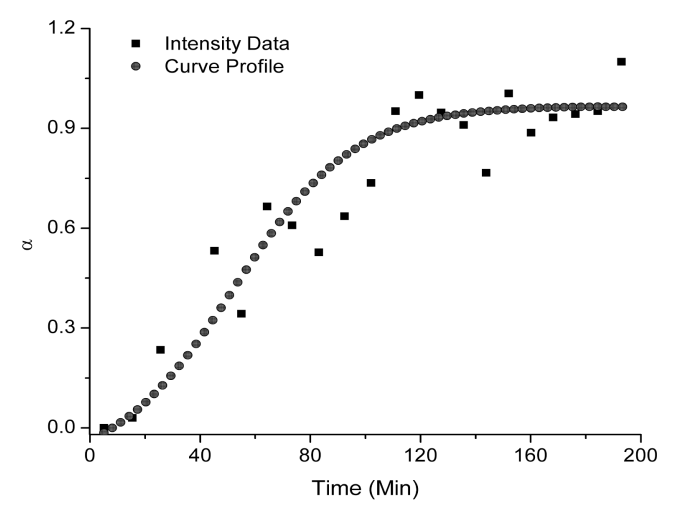

(b)

Figure 2. (a) WAXS data detailing the evolution of crystalline ZnAPO-34 collected during the combined SAXS/WAXS/XAFS/Raman data recorded in situ during the heating of a $\mathrm{ZnAPO}$ gel $\left(30 \% \mathrm{Zn}^{2+}\right)$ at $70{ }^{\circ} \mathrm{C}$ as a function of time. (b) Extent of crystallization $(\alpha)$ curve for $30 \% \mathrm{ZnAPO}-34$ versus reaction time at $70^{\circ} \mathrm{C}$. The data were generated by profiling the $-120 /-210$ reflection at peak at $17.7^{\circ} 2 \theta$.
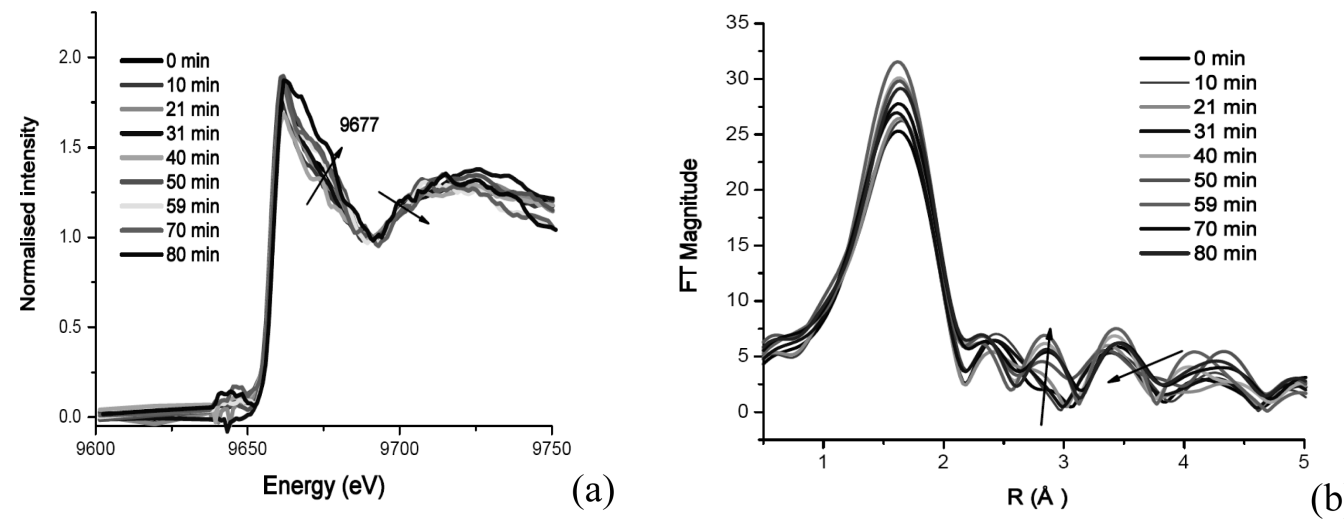

Figure 3. (a) Zn K-edge XANES spectra obtained during combined SAXS/WAXS/XAFS/Raman measurements recorded in situ during the heating of a $\mathrm{ZnAPO}$ gel $\left(30 \% \mathrm{Zn}^{2+}\right)$ at $70^{\circ} \mathrm{C}$ as a function of time. The two features highlighted demonstrate the changes that occur during crystallization. In (b) is shown the evolution of the changes in the $\mathrm{k}^{3}$ weighted $\mathrm{Zn}$ K-edge EXAFS data during hydrothermal crystallization of ZnAPO-34, recorded during a second in situ experiment using a hydrothermal cell. The corresponding XAFS and accompanying XRD data are shown in FigureS8a.

Table 1. EXAFS Refinement Performed on Both the Initial 30\% Containing ZnAPO-34 Synthesis Gel and the Final ZnAPO-34 Material

\begin{tabular}{|c|c|c|c|c|c|}
\hline sample & $N$ & $\mathrm{Me}-\mathrm{S}^{a}$ distance $R(\AA)$ & $2 \sigma^{2}\left(\AA^{2}\right)$ & $E^{0}$ & $R$-factor (\%) \\
\hline \multirow[t]{3}{*}{ ZnAPO (30\%) gel } & 4.1 & $1.93(\mathrm{O})$ & 0.014 & -17.03 & 14.13 \\
\hline & 2 & $3.20(\mathrm{P})$ & 0.030 & & \\
\hline & 2 & $3.55(\mathrm{P})$ & 0.019 & & \\
\hline \multirow[t]{5}{*}{ ZnAPO (30\%) crystalline material } & 4.1 & $1.93(\mathrm{O})$ & 0.05 & -19.78 & 21.10 \\
\hline & 1 & $3.36(\mathrm{P})$ & 0.01 & & \\
\hline & 1 & $3.20(\mathrm{P})$ & 0.01 & & \\
\hline & 1 & $3.11(\mathrm{P})$ & 0.01 & & \\
\hline & 1 & $3.41(\mathrm{P})$ & 0.01 & & \\
\hline
\end{tabular}

${ }^{a} \mathrm{~S}=$ scatterer defined in parentheses after each bond distance.

lower coordination number for $\mathrm{Zn}-\mathrm{P}$ observed in the starting gel is unlikely to be due to actual under-coordination but may reflect a higher degree of disorder in the $\mathrm{Zn}$ environment at this stage.

Raman Data. Part of the time-resolved in situ Raman spectra collected at the same time as the X-ray data are given in Figure 4. The stacked data set focuses on a region of the spectra where notable changes occur during the experiment. The two Raman bands located at 665 and $675 \mathrm{~cm}^{-1}$ are known to be sensitive to the two conformer states of the TEA cation, the $\operatorname{tg} \cdot \operatorname{tg}\left(S_{4}\right.$ symmetry) and $\mathrm{tt} \cdot \mathrm{tt}\left(D_{2 d}\right)$ forms, respectively. ${ }^{24,41,53}$ The Raman band at $675 \mathrm{~cm}^{-1}$ due to the $\mathrm{tt} \cdot \mathrm{tt}$ conformer is more intense at the onset (intensity ratio 675:665 $\mathrm{cm}^{-1}$ of 1:1.2), suggesting that this conformer is more prevalent in the initial gel. However, the relative intensity of these two bands changes during the course of the experiment, particularly as crystallization begins. ${ }^{24}$ 


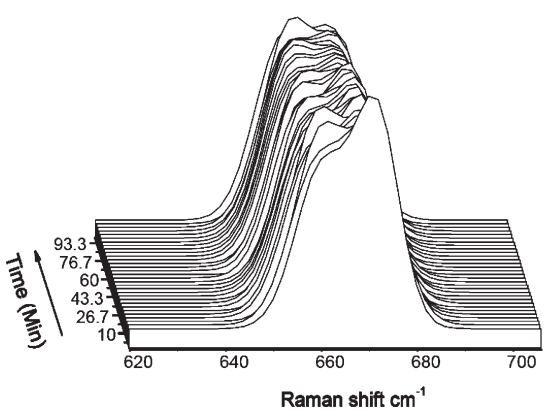

(a)

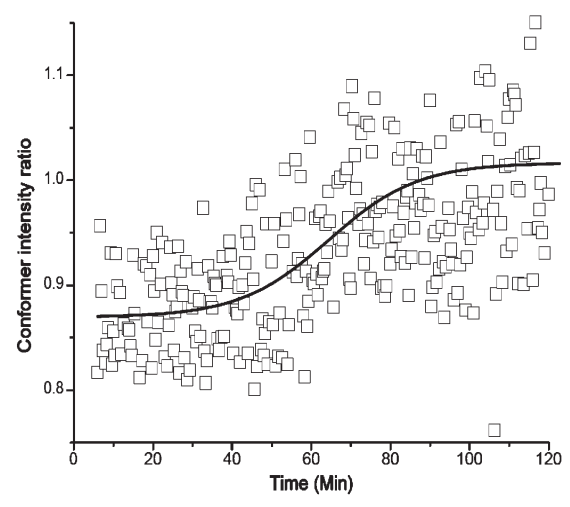

(b)

Figure 4. (a) Portion of the Raman spectra obtained during combined SAXS/WAXS/XAFS/Raman measurements recorded in situ during the heating of a $\mathrm{ZnAPO}$ gel $\left(30 \% \mathrm{Zn}^{2+}\right)$ at $70{ }^{\circ} \mathrm{C}$. (b) A time-resolved analysis of the ratio of $\mathrm{tg} \cdot \mathrm{tg}$ to $\mathrm{tt} \cdot \mathrm{tt}$ conformers.

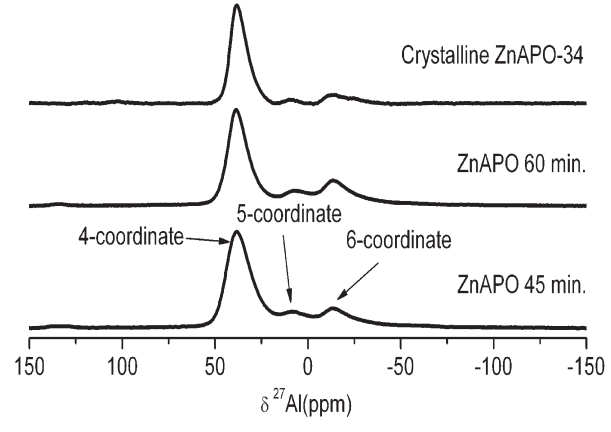

(a)

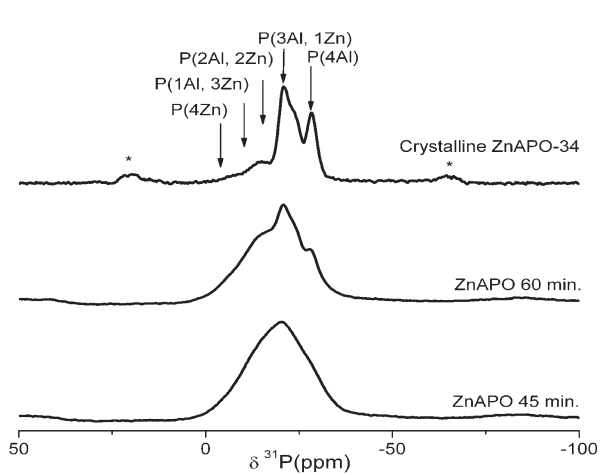

(b)

Figure 5. ${ }^{27} \mathrm{Al}$ (a) and ${ }^{31} \mathrm{P}$ MAS NMR (b) recorded on $\mathrm{ZnAPO}\left(20 \% \mathrm{Zn}^{2+}\right.$ loading) after 45 and 60 min of reaction at $70{ }^{\circ} \mathrm{C}$. For the ${ }^{31} \mathrm{P} \mathrm{NMR} \mathrm{spectra,}$ resonances due to the different types of $\mathrm{P}$ environments within the crystalline $\mathrm{ZnAPO}$ material have been highlighted. In (b), the presence of the spinning side bands is marked with an asterisk.

The changes in relative band intensity as a function of time are more clearly illustrated in Figure 4b, which shows a trend whereby the proportion of the $\mathrm{tg} \cdot \mathrm{tg}$ form increases during ZnAPO-34 crystallization. The similarity of this plot to the WAXS peak intensity profile in Figure $2 \mathrm{~b}$ suggests a correlation between the change in conformer state and the formation of crystalline product. Indeed, both plots contain a discernible slope 20-30 min into the reaction. In addition to the relative intensity change, we observe a sharpening (fwhm decrease) for both bands during the experiment, suggestive of encapsulation of both forms of the template within the ZnAPO34 framework.

Post-Synthesis Sample Characterization. A detailed ex situ post reaction analysis of the crystalline ZnAPO-34 material has also been performed in an attempt to further understand the cause and significance of some of the changes observed during the in situ study and to shed further light into the self-assembly processes.

NMR. Figure 5 contains ${ }^{27} \mathrm{Al}$ and ${ }^{31} \mathrm{P}$ MAS NMR spectra recorded on filtered and dried samples that had undergone hydrothermal reaction in Teflon-lined autoclaves at $70{ }^{\circ} \mathrm{C}$ for 45,60 , and $120 \mathrm{~min}$, which resulted in amorphous, partially crystalline, and crystalline materials, respectively (Supporting Information Figure S11). The ${ }^{27} \mathrm{Al} \mathrm{NMR}$ spectra appear very similar to each other and comprise symmetrical resonances at $\delta=39 \mathrm{ppm}$ (most intense), 8.2 ppm (very weak), and $-13.1 \mathrm{ppm}$ (weak), assignable to the presence of tetrahedral $\mathrm{Al}^{3+}$ (majority), penta-coordinated, and octahedrally coordinated $\mathrm{Al}^{3+}$, respectively. The fact that the spectra are so similar to each other, irrespective of sample crystallinity, suggests that $\mathrm{Al}^{3+}$ is in a similar coordination environment before crystallization as in the final crystalline material. This suggests that not all $\mathrm{Al}^{3+}$ species are necessarily "converted" or incorporated into tetrahedral framework positions and therefore that a certain amount of $\mathrm{Al}^{3+}$ could be contained in amorphous species.

In contrast to the ${ }^{27} \mathrm{Al} \mathrm{NMR}$ data, the ${ }^{31} \mathrm{P} \mathrm{NMR}$ spectra continuously evolve over the course of reaction. After $45 \mathrm{~min}$ of reaction, only a broad resonance around $\delta=-20.4 \mathrm{ppm}$ can be seen. After $60 \mathrm{~min}$, while the broad resonance remains, three additional resonances are now discernible, appearing as shoulders on the initial broad band at $\delta$ of $-14.1,-20.7$, and $-28 \mathrm{ppm}$, respectively. After $120 \mathrm{~min}$ of reaction, the broad resonance then disappears, revealing four separate resonances at $\delta$ of $-10.6,-14.1,-20.7$, and $-28 \mathrm{ppm}$. Such resonances have previously been shown to be due to various tetrahedral phosphorus environments of the type $\mathrm{P}-\mathrm{O}_{4}-\mathrm{Al}_{4-n} \mathrm{Me}_{n}$ in microporous materials. ${ }^{54,55}$ The dominant resonances in the $120 \mathrm{~min}$ crystalline sample then can be assigned to the presence of $\mathrm{P}(4 \mathrm{Al})$ and $\mathrm{P}(3 \mathrm{Al}, 1 \mathrm{Zn})$ environments and strongly suggest that $\mathrm{Zn}^{2+}$ in the final crystalline phase is well dispersed. ${ }^{56}$ However, before crystallization occurs, the presence of a broad symmetrical resonance suggests that the phosphorus environment is both poorly dispersed, poorly ordered, and that a large number of $\mathrm{P}-$ $\mathrm{O}-\mathrm{Zn}$ interactions exist.

Powder Diffraction Refinement. Refined powder diffraction data collected for the crystalline ZnAPO-34 material are given in 


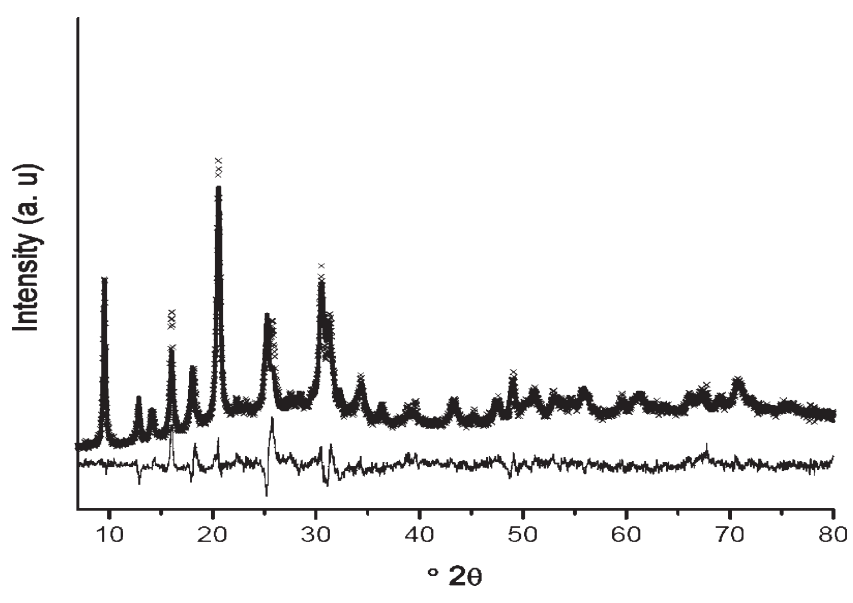

Figure 6. Refined XRD powder data for $20 \%$ ZnAPO-34. Key: ( $\times$, $\left.Y_{\text {obs }}\right)$, (thick,$\left.- Y_{\text {calc }}\right)$, and $(-$, difference).

Table 2. ZEBEDDE Energy Minimization Calculations for TEA $^{+}$Templates within the Cages of the CHA Structure ${ }^{a}$

\begin{tabular}{ccc} 
conformer configuration & no. of templates & lowest $E_{\text {inter }}\left(\mathrm{kJ} \mathrm{mol}^{-1}\right)$ \\
$\mathrm{tt} \cdot \mathrm{tt}$ & 1 & -102 \\
$\mathrm{tg} \cdot \mathrm{tg}$ & 1 & -98 \\
$\mathrm{tt} \cdot \mathrm{tt} / \mathrm{tt} \cdot \mathrm{tt}$ & 2 & +632 \\
$\mathrm{tg} \cdot \mathrm{tg} / \mathrm{tt} \cdot \mathrm{tt}$ & 2 & +1596 \\
$\mathrm{tg} \cdot \mathrm{tg} / \mathrm{tg} \cdot \mathrm{tg}$ & 2 & +1587 \\
${ }^{a}$ Note that $E_{\text {inter }}$ is calculated per TEA mole. & \\
\hline
\end{tabular}

Figure 6. The pattern contains peaks pertaining solely to the ZnAPO-34 phase, and a good fit of the data was obtained in the $R \overline{3}$ space group, suggesting that there is no evidence for the preferential location/site ordering of $\mathrm{Zn}^{2+}$ within the structure (causing a lowering in the symmetry of the unit cell to $R 3$ ) as previously proposed in $\mathrm{Co}^{2+}$ containing systems with similar loadings. ${ }^{57} \mathrm{~A}$ broad background signal over the $2 \theta$ range of $12-$ $37^{\circ}$ is also consistent with the presence of additional poorly crystalline material (i.e., unreacted amorphous material) as suggested by ${ }^{27} \mathrm{Al}$ NMR. The amount of uncrystallized material appears, however, to decrease when the $\mathrm{Zn}$ substitution increases from 20 to 30\%, as can be seen when comparing Figure 6 with Supporting Information Figure S11.

Template Loading. The number of template molecules and their conformer states within the microporous CHA framework have been examined using ZEBEDDE calculations. In Table 2, we show the results of packing up to either 1 or 2 TEA molecules (considering rigid forms of both conformer states) into the cages. Far more favorable interaction energies (negative values) were observed with 1 template molecule in the cage rather than with two (highly positive values), and the $\mathrm{tt} \cdot \mathrm{tt}$ state is energetically preferred. Because the difference in energy is only $+4 \mathrm{~kJ} / \mathrm{mol}$, there is only a small preference for one of the conformer states within the structure. The high interaction energies when two template molecules are present may explain why it is not possible to prepare a highly substituted ([Zn] > 30\%) ZnAPO-34 structure with this structure-directing agent.

We also compare the binding of the TEA in CHA (Table 2) with that in the AFI framework (Supporting Information Table S2). There is clearly a stronger energetic "templating effect" between the TEA and CHA than with AFI. These results correlate well with previous work on the influence of triethylamine as a template in CHA/AFI. ${ }^{58}$

TEM. TEM images recorded on a crystallized sample are shown in Figure 7a, while an accompanying electron diffraction pattern recorded from the same sample is given in Figure $7 \mathrm{~b}$. The TEM images reveal a large aggregate of square particles with squared-off edges. Some of these particles are small (ca. $20 \mathrm{~nm})$, while others appear much larger (ca. $\geq 60 \mathrm{~nm}$ ). This material is clearly crystalline as evidenced by the electron diffraction pattern in Figure $7 \mathrm{~b}$, although it contains also some diffraction amorphous material by dint of some species containing more rounded edges.

\section{DISCUSSION}

As with the crystallization of other microporous zeolites and aluminophosphates, formation of $\mathrm{ZnAPO}-34$ with the $\mathrm{CHA}$ structure occurs from a highly heterogeneous solution containing both simple hydrated cationic and anionic species as well as increasingly complex polymeric amorphous aggregates. Although this heterogeneity makes it difficult to determine unequivocally the key components in the growth and formation of the final $\mathrm{ZnAPO}-34$ material, our approach, whereby results from the combined in situ study are considered alongside measurements and observations made from separate ex situ studies, allows us to identify important steps during the stages of ZnAPO-34 self-assembly.

First, let us consider the changes that occur at the atomic level for the framework components during $\mathrm{ZnAPO}-34$ formation. Beginning with $\mathrm{Zn}^{2+}$, we observe that the first neighbor environment does not change during crystallization because $\mathrm{Zn}^{2+}$ ions remain tetrahedrally coordinated to four oxygens throughout. In the second shell, however, EXAFS shows evidence for an initial $\mathrm{Zn}-\mathrm{O}-\mathrm{P}$ local environment (disordered), which becomes more ordered as the final crystalline material forms. Unfortunately, it was not possible using either Raman or ${ }^{31} \mathrm{P}$ NMR to determine the presence of any $\mathrm{Zn}-\mathrm{O}-\mathrm{Al}-\mathrm{O}-\mathrm{P}$ containing species in the initial gel as the spectroscopic signal for such species are too similar to those of $\mathrm{Zn}-\mathrm{O}-\mathrm{P}$ or $\mathrm{Al}-\mathrm{O}-$ $\mathrm{P}$. Analysis of the ${ }^{31} \mathrm{P}$ NMR data for the quenched and dried samples suggests that these evolve during hydrothermal treatment. Interestingly, the evolution of a shoulder resonance $(\delta=-$ $14.1 \mathrm{ppm}$ ) after $60 \mathrm{~min}$ might hint at possible $\mathrm{Zn}^{2+}$ "zoning” (i.e., multiple $\mathrm{P}-\mathrm{O}-\mathrm{Al}_{4-x} \mathrm{Zn}_{x}$ where $x>1$ ) rather than a random, well-dispersed distribution as seen for the final material. One should, however, interpret such spectra with caution because the quenching and recovery process may induce additional changes within the sample that might not occur under hydrothermal conditions.

Of greater interest then is the behavior of $\mathrm{Al}^{3+}$, which, unlike $\mathrm{Zn}^{2+}$ and $\mathrm{P}^{5+}$, undergoes a local coordination change from octahedral (Figure S4a) to tetrahedral (Figure 5a) during reaction. The quenching study also suggests that this change occurs before crystallization begins, although it is not clear again whether if this occurs as a result of the quenching and drying procedure.

Considering now the changes at the nanoscale during the synthesis, we discuss the significance of the changes in SAXS and WAXS data. From the SAXS data, it was possible to observe a rather broad size distribution (modal size from SAXS estimated to be ca. $32-37 \mathrm{~nm}$, which fits well with the size distribution observed using TEM). Such species are probably also responsible 


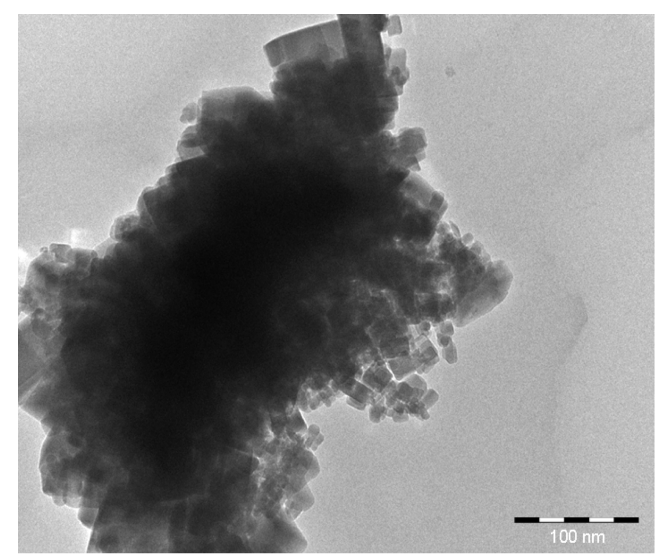

(a)

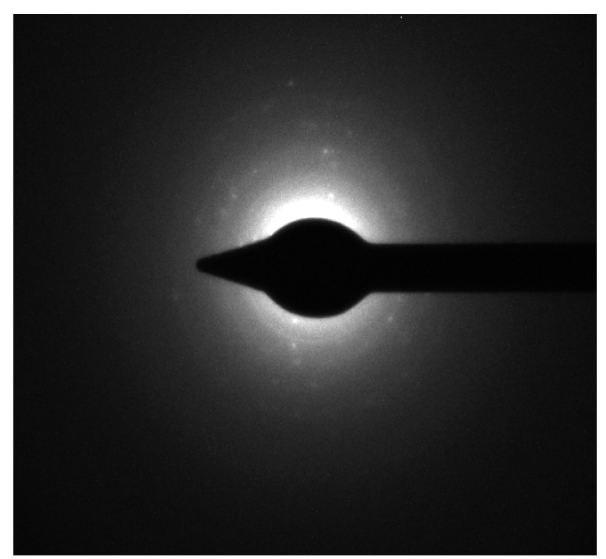

(b)

Figure 7. (a) Transmission electron micrograph of a crystalline $20 \% \mathrm{Zn}^{2+}$ containing $\mathrm{ZnAPO}-34$ particle, and (b) the accompanying electron diffraction data reveal that the particle possesses long-range order.

for the amorphous background on the WAXS data as well as the part of the ${ }^{31}$ P MAS NMR signal with $\delta$ higher (less negative) than $-20 \mathrm{ppm}$. Nanoparticulate species are commonly observed in both zeolite and zeotype crystallization, although, in contrast to these previous studies, we observe a number of notable differences. First, the initial species are much larger than those typically observed (around 3 times larger than those seen previously for aluminophosphate formation and 6-15 times larger than the primary particles seen during zeolite formation). Second, there is little growth during the initial stages of heat treatment (the centroid position remains relatively unchanged); however, the signal intensity is observed to decrease. Third, while two nanoparticle populations have been observed previously for zeolite systems, the behavior of these two populations is different. In zeolite synthesis, usually small "primary" particles are initially observed, followed by larger secondary nanoparticles as the primary particles are consumed, whereas here we observe the second population forming at higher $q$ (i.e., smaller particles), while the original signal is still present. This second population is coincident with the formation of crystalline material observed in the WAXS data, and we note that all of these observations are consistently reproducible for this synthesis system irrespective of $[\mathrm{Zn}]$ concentration (see Figure S14). The importance of the initial SAXS population, that is, whether it is a prerequisite for the initiation of crystallization, on ZnAPO-34 crystallization is not clear, although in this study a decrease in signal intensity for the initial species (we note that the amorphous background in the WAXS signal at the beginning also disappears) always precedes crystallization. Several possible transformation mechanisms need to be considered, for example, solution-mediated transformation, solid-state rearrangement, epitaxial crystallization, or surfacemediated transformation. However, it is difficult to rationalize the presence of two populations in the SAXS signal in which the size of the initial amorphous component is twice that of the crystalline species other than via a solution-mediated transport process. We note, however, that it is not possible to rule out completely that direct formation of crystalline $\mathrm{ZnAPO}-34$ via a solid-state rearrangement mechanism could occur under hydrothermal conditions, because steam-assisted conversion (SAC) experiments performed for $4 \mathrm{~h}$ at $140^{\circ} \mathrm{C}$ on an air-dried $\mathrm{ZnAPO}$ gel with the same composition $\left(1.5 \mathrm{H}_{3} \mathrm{PO}_{4}: 0.7 \mathrm{Al}\left(\mathrm{OH}_{3}\right) \cdot y \mathrm{H}_{2}\right.$ $\mathrm{O}: 0.3\left(\mathrm{CH}_{3} \mathrm{COO}\right)_{2} \mathrm{Zn} \cdot 2 \mathrm{H}_{2} \mathrm{O}: 0.8 \mathrm{TEAOH}: 26 \mathrm{H}_{2} \mathrm{O}$ ) (resultant
XRD patterns given in Figure S14) also produced predominantly ZnAPO-34; the appearance of peaks due to a "pre-" or cocrystallized layered phase hints at a formation mechanism involving layered intermediates. ${ }^{20,59}$

Now, we examine the mitigating factors behind the formation of the ZnAPO-34 structure. As has been shown previously, the presence of $\mathrm{Zn}^{2+}$ (and other metal $(\mathrm{Me})^{2+}$ charged species) plays a key role in structure direction; the presence of $2+$ ions clearly directs the formation of MeAPO-34 over MeAPO-5. It has been observed that increasing amounts of $\mathrm{Zn}^{2+}$ result in both a greater amount of crystalline material and a greater proportion of the $\operatorname{tg} \cdot \operatorname{tg}$ conformer in the system. ${ }^{24}$ From the in situ data, we observe that changes in this conformer ratio appear coincident with the formation of crystalline material. We note, however, that it is not possible from these data to determine whether the conformer state changes immediately before or after the onset of crystalline material formation. The significance of the template conformer ratio change is not clear, but it is most likely that the cause of this change is the removal of the template molecules out of solution and subsequent encapsulation ( 1 per cage) within the microporous structure. One TEA template molecule per cage has enough freedom to adopt either conformer state within the CHA cage (the difference in conformational energy is small, ca. $4 \mathrm{~kJ}$ $\mathrm{mol}^{-1}$ ), whereas in the initial TEAOH solution strong intermolecular forces mean the $\mathrm{tt} \cdot \mathrm{tt}$ conformer state predominates. Such a proposal could explain why with increasing $\mathrm{Zn}^{2+}$ concentrations, increasing amounts of crystalline material are observed along with more of the $\mathrm{tg} \cdot \mathrm{tg}$ conformer as more of the template is encapsulated within the microporous material than in solution. Raman spectroscopy can in such circumstances therefore yield indirect evidence of the extent of crystallization of microporous materials and thus could be considered as an alternative to X-rays/addition to X-rays for the monitoring of crystallization behavior.

The question then still remains as to the structure-directing role of $2+$ ions. In particular, why does the CHA structure form at low temperatures in the presence of $2+$ ions, and why does it do so in preference to AFI $?^{60}$ Dealing with the latter part first, we observe in Supporting Information Figure S15 (and Table S2) that relaxed TEA cations within the AFI channel pack with a density equal to one template molecule for two adjoining 12membered rings. Considering that every $\mathrm{T}$-atom in the structure 
forms part of a 12 ring, then from a charge compensation perspective, the framework will tolerate the replacement of $1 / 12$ of the $\mathrm{Al}^{3+}$ ions by a $2+$ ion or approximately $8.33 \%$ substitution to remain iso-neutral. Thus, this simple consideration of charge compensation allows us to propose that substitution levels greater than $8.33 \%$ of $\mathrm{Al}^{3+}$ by a $2+$ ion with this template are unlikely in the AFI structure.

Addressing then the former point, the low temperature exclusive crystallization of ZnAPO-34 may be due to the stabilization of molecular/ionic $\mathrm{ZnPO}$ species identical to that found in the final $\mathrm{CHA}$ phase, for example, $\mathrm{Zn}^{2+}$-rich four-membered rings akin to those proposed playing an important role in the crystallization of polymeric zinc phosphate structures. ${ }^{61}$ XAFS, Raman, and to some extent NMR data of the quenched precrystalline samples suggest some evidence for $\mathrm{Zn}^{2+}$-rich phosphate species, although there is no evidence for such species in the final crystalline material, the data being entirely consistent with a random distribution of $\mathrm{Zn}^{2+}$. If then such $\mathrm{Zn}^{2+}$-rich phosphate structure species do form initially, their role as building blocks leading to the preferential crystallization of CHA is therefore at best an indirect one because they are clearly not stable.

Clearly, the crystallization of the Zn-rich containing CHA phase requires charge balancing to stabilize the final crystalline product, but it is likely that this also plays an important role at an earlier stage. We propose that the TEA cation plays an initial role in stabilizing noncrystalline $\mathrm{Zn}-\mathrm{O}-\mathrm{P}-\mathrm{O}-\mathrm{Al}$ species (because charge compensation from anionic species such as hydroxides is not likely to be present in significant amounts at such low $\mathrm{pH}$ ) before later going on to act as a templating agent around which the CHA structure can form. ${ }^{62}$ Therefore, such disordered $\mathrm{Zn}-$ $\mathrm{O}-\mathrm{P}-\mathrm{O}-\mathrm{Al}-\mathrm{TEA}^{+}$species act as a form of critical nuclei, and indeed we observe that with increasing $[\mathrm{Zn}]$ the SAXS signal intensity and the amount of crystalline material increase, yet there appears no large difference in the size of the final crystalline particles, an effect consistent with increased nucleation. We observe, however, from TEM measurements that not all $\mathrm{Zn}$ containing species go on to form crystalline ZnAPO-34, most probably due to local variation in sample homogeneity. Such species might, however, provide nutrient for further crystal growth. ${ }^{63,64}$

\section{CONCLUSIONS}

Summarizing, we observe the following during ZnAPO-34 crystallization from a gel: (a) Crystallization occurs from a gel, which after initial mixing is highly heterogeneous. During hydrothermal treatment, the atomic constituents become increasingly homogeneous, in what is likely to be a precondition for crystallization. (b) The population of nanoparticles decreases as formation of $\mathrm{ZnAPO}-34$ begins, although it is not clear whether the crystallization process is dependent upon this. (c) Increasing amounts of $\mathrm{Zn}^{2+}$ ions result in both larger nanoparticulate aggregates and in the formation of more crystalline material. Clearly then, $\mathrm{Zn}^{2+}$ plays a nucleating role in the formation of $\mathrm{ZnAPO}-34$. (d) The changes in the TEA cation conformer state ratio are related to the formation of crystalline $\mathrm{ZnAPO}-34$. (e) $\mathrm{Zn}^{2+}$ ions are largely homogeneously distributed throughout the crystalline sample. We observe no evidence for the preferential location of $\mathrm{Zn}^{2+}$ species that would suggest the presence of stabilized structural units/building blocks essential to the formation of $\mathrm{ZnAPO}-34$. (f) We propose that the preferential formation of CHA over AFI is most likely determined at the point of noncrystalline $\mathrm{Zn}-\mathrm{O}-\mathrm{P}-\mathrm{O}-\mathrm{Al}$ formation. (g) A close interaction between such species and the $\mathrm{TEA}^{+}$then results in a "nuclei" around which the CHA cages could form. ${ }^{62}$

Thus, a number of key steps in the formation process of this material have been identified, and such information could be used to control the outcome of an aluminophosphate synthesis and how properties such as the extent of crystallization, crystallite size, etc., can be controlled. However, we note that despite this there are still a number of questions that remain unanswered, namely and most importantly, how does the ZnAPO-34 material form, and what are the key species involved? For this, more detailed insight at the atomic level is required, and such information might be obtainable when using techniques such as ESI MS or AFM. Only when this information is known can rational design be possible.

\section{ASSOCIATED CONTENT}

S Supporting Information. Supplementary figures ( $\mathrm{S} 1-$ 15) and additional experimental information. This material is available free of charge via the Internet at http://pubs.acs.org.

\section{AUTHOR INFORMATION}

\section{Corresponding Author}

*Tel.: 0031 (0) 30253 6815. Fax: 0031 (0) 30251 1027. E-mail: a.m.beale@uu.nl (A.M.B.); b.m.weckhuysen@uu.nl (B.M.W.)

\section{ACKNOWLEDGMENT}

Financial support from NWO-CW (VENI project for A.M.B.) and NRSC-C (B.M.W.) is acknowledged. NWO is also thanked for beamtime at ESRF (BM26A). We wish to acknowledge the assistance and advice of Hans Meeldijk in performing the TEM measurements.

\section{REFERENCES}

(1) Cundy, C. S.; Cox, P. A. Chem. Rev. 2003, 103, 663-701.

(2) Cundy, C. S.; Cox, P. A. Microporous Mesoporous Mater. 2005, $82,1-78$.

(3) Davis, M. E. Nature 2002, 417, 813-821.

(4) Yu, J. H.; Xu, R. R. Acc. Chem. Res. 2003, 36, 481-490.

(5) Yu, J. H.; Xu, R. R. Chem. Soc. Rev. 2006, 35, 593-604.

(6) Davis, T. M.; Drews, T. O.; Ramanan, H.; He, C.; Dong, J. S.; Schnablegger, H.; Katsoulakis, M. A.; Kokkoli, E.; McCormick, A. V.; Penn, R. L.; Tsapatsis, M. Nat. Mater. 2006, 5, 400-408.

(7) Kirschhock, C. E. A.; Kremer, S. P. B.; Vermant, J.; Van Tendeloo, G.; Jacobs, P. A.; Martens, J. A. Chem.-Eur. J. 2005, $11,4306-4313$.

(8) Mintova, S.; Olson, N. H.; Valtchev, V.; Bein, T. Science 1999, 283, 958-960.

(9) Chen, B.; Huang, Y. J. Phys. Chem. C 2007, 111, 15236-15243.

(10) Dong, M.; Wang, G. F.; Qin, Z. F.; Wang, J. G.; Liu, T.; Yuan, S. P.; Jiao, H. J. J. Phys. Chem. A 2007, 111, 1515-1522.

(11) Xu, R. S.; Shi, X. C.; Zhang, W. P.; Xu, Y. P.; Tian, Z. J.; Lu, X. B.; Han, X. W.; Bao, X. H. Phys. Chem. Chem. Phys. 2010, 12, 2443-2449.

(12) Xu, R. S.; Zhang, W. P.; Guan, J.; Xu, Y. P.; Wang, L.; Ma, H. J.; Tian, Z. J.; Han, X. W.; Lin, L. W.; Bao, X. H. Chem.-Eur. J. 2009, $15,5348-5354$.

(13) Aerts, A.; Kirschhock, C. E. A.; Martens, J. A. Chem. Soc. Rev. 2010, 39, 4626-4642.

(14) Arieli, D.; Delabie, A.; Groothaert, M.; Pierloot, K.; Goldfarb, D. J. Phys. Chem. B 2002, 106, 9086-9097. 
(15) Beale, A. M.; van der Eerden, A. M. J.; Grandjean, D.; Petukhov, A. V.; Smith, A. D.; Weckhuysen, B. M. Chem. Commun. 2006, 4410-4412.

(16) Beale, A. M.; van der Eerden, A. M. J.; Jacques, S. D. M.; Leynaud, O.; O’Brien, M. G.; Meneau, F.; Nikitenko, S.; Bras, W.; Weckhuysen, B. M. J. Am. Chem. Soc. 2006, 128, 12386-12387.

(17) Chen, B. H.; Kirby, C. W.; Huang, Y. N. J. Phys. Chem. C 2009, $113,15868-15876$.

(18) Fan, F. T.; Feng, Z. C.; Li, C. Acc. Chem. Res. 2010, 43, 378-387.

(19) Fan, F. T.; Feng, Z. C.; Sun, K. J.; Guo, M. L.; Guo, Q.; Song, Y.; Li, W. X.; Li, C. Angew. Chem., Int. Ed. 2009, 48, 8743-8747.

(20) Grandjean, D.; Beale, A. M.; Petukhov, A. V.; Weckhuysen, B. M. J. Am. Chem. Soc. 2005, 127, 14454-14465.

(21) Muncaster, G.; Davies, A. T.; Sankar, G.; Catlow, C. R. A.; Thomas, J. M.; Colston, S. L.; Barnes, P.; Walton, R. I.; O’Hare, D. Phys. Chem. Chem. Phys. 2000, 2, 3523-3527.

(22) Nikitenko, S.; Beale, A. M.; van der Eerden, A. M. J.; Jacques, S. D. M.; Leynaud, O.; O’Brien, M. G.; Detollenaere, D.; Kaptein, R.; Weckhuysen, B. M.; Bras, W. J. Synchrotron Radiat. 2008, 15, 632-640.

(23) Norby, P.; Hanson, J. C. Catal. Today 1998, 39, 301-309.

(24) O’Brien, M. G.; Beale, A. M.; Catlow, C. R. A.; Weckhuysen,

B. M. J. Am. Chem. Soc. 2006, 128, 11744-11745.

(25) O’Brien, M. G.; Beale, A. M.; Weckhuysen, B. M. Chem. Soc. Rev. 2010, 39, 4767-4782.

(26) O’Brien, M. G.; Sanchez-Sanchez, M.; Beale, A. M.; Lewis, D. W.; Sankar, G.; Catlow, C. R. A. J. Phys. Chem. C 2007, 111, 16951-16961.

(27) Sankar, G.; Bras, W. Catal. Today 2009, 145, 195-203.

(28) Sankar, G.; Thomas, J. M.; Rey, F.; Greaves, G. N. J. Chem. Soc., Chem. Commun. 1995, 2549-2550.

(29) Simmance, K.; Sankar, G.; Bell, R. G.; Prestipino, C.; van Beek, W. Phys. Chem. Chem. Phys. 2010, 12, 559-562.

(30) Vistad, Ø. B.; Akporiaye, D. E.; Taulelle, F.; Lillerud, K. P. Chem. Mater. 2003, 15, 1639-1649.

(31) Vistad, Ø. B.; Akporiaye, D. E.; Taulelle, F.; Lillerud, K. P. Chem. Mater. 2003, 15, 1650-1654.

(32) Weckhuysen, B. M.; Baetens, D.; Schoonheydt, R. A. Angew. Chem., Int. Ed. 2000, 39, 3419-3421.

(33) Wragg, D. S.; Byrne, P. J.; Giriat, G.; Le Ouay, B.; Gyepes, R.; Harrison, A.; Whittaker, A. G.; Morris, R. E. J. Phys. Chem. C 2009, 113, 20553-20558.

(34) van Santen, R. A. Nature 2006, 444, 46-47.

(35) Baerlocher, C.; McCusker, L. B.; Olson, D. H. Atlas of Zeolite Framework Types, 6th revised ed.; Elsevier: Amsterdam, 2007.

(36) Bentrup, U.; Radnik, J.; Armbruster, U.; Martin, A.; Leiterer, J.; Emmerling, F.; Bruckner, A. Top. Catal. 2009, 52, 1350-1359.

(37) Jacques, S. D. M.; Leynaud, O.; Strusevich, D.; Stukas, P.; Barnes, P.; Sankar, G.; Sheehy, M.; O’Brien, M. G.; Iglesias-Juez, A.; Beale, A. M. Catal. Today 2009, 145, 204-212.

(38) Blanton, T. N.; Barnes, C. L.; Lelental, M. J. Appl. Crystallogr. 2000, 33, 172-173.

(39) Binsted, N. C.; Campbell, J. W.; Gurman, S. J.; Stephenson, P. C. EXAFS Analysis Programs; Daresbury Laboratory: Warrington, 1991.

(40) Ravel, B.; Newville, M. J. Synchrotron Radiat. 2005, 12, 537-541.

(41) Naudin, C.; Bonhomme, F.; Bruneel, J. L.; Ducasse, L.; Grondin, J.; Lassegues, J. C.; Servant, L. J. Raman Spectrosc. 2000, 31, 979-985.

(42) Coelho, A. A. TOPAS-Academic, Version 4.1; Coelho Software: Brisbane, Australia, 2007.

(43) Meden, A.; Novak, N.; Kaucic, V. Mater. Sci. Forum 1994, $166,613-618$

(44) Thompson, P.; Cox, D. E.; Hastings, J. M. J. Appl. Crystallogr. 1987, 20, 79-83.

(45) Jelfs, K. E.; Slater, B.; Lewis, D. W.; Willock, D. J. Stud. Surf. Sci. Catal. 2007, 170B, 1685-1692.

(46) Lewis, D. W.; Freeman, C. M.; Catlow, C. R. A. J. Phys. Chem. 1995, 99, 11194-11202.
(47) Lewis, D. W.; Willock, D. J.; Catlow, C. R. A.; Thomas, J. M.; Hutchings, G. J. Nature 1996, 382, 604-606.

(48) Sun, H.; Mumby, S. J.; Maple, J. R.; Hagler, A. T. J. Am. Chem. Soc. 1994, 116, 2978-2987.

(49) Gale, J. D.; Henson, N. J. J. Chem. Soc., Faraday Trans. 1994, 90, 3175-3179.

(50) Gale, J. D.; Rohl, A. L. Mol. Simul. 2003, 29, 291-341.

(51) Tusar, N. N.; Kaucic, V.; Geremia, S.; Vlaic, G. Zeolites 1995, $15,708-713$.

(52) Waychunas, G. A.; Fuller, C. C.; Davis, J. A.; Rehr, J. J. Geochim. Cosmochim. Acta 2003, 67, 1031-1043.

(53) Brand, H. V.; Curtiss, L. A.; Iton, L. E.; Trouw, F. R.; Brun, T. O. J. Phys. Chem. 1994, 98, 1293-1301.

(54) Akporiaye, D. E.; Andersen, A.; Dahl, I. M.; Mostad, H. B.; Wendelbo, R. J. Phys. Chem. 1995, 99, 14142-14148.

(55) Barrie, P. J.; Klinowski, J. J. Phys. Chem. 1989, 93, 5972-5974.

(56) Blasco, T.; Fernandez, L.; Martinez-Arias, A.; Sanchez-Sanchez, M.; Concepcion, P.; Nieto, J. M. L. Microporous Mesoporous Mater. 2000, 39, 219-228.

(57) Stephenson, R. A. Ph.D. Thesis, University of Newcastle, 2003.

(58) Lewis, D. W.; Catlow, C. R. A.; Thomas, J. M. Chem. Mater. 1996, 8, 1112-1118.

(59) Vistad, Ø. B.; Akporiaye, D. E.; Lillerud, K. P. J. Phys. Chem. B 2001, 105, 12437-12447.

(60) Sanchez-Sanchez, M.; Serrano, D. P.; van Grieken, R.; Melero, J. A. Stud. Surf. Sci. Catal. 2007, 170, 499-505.

(61) Natarajan, S.; van Wullen, L.; Klein, W.; Jansen, M. Inorg. Chem. 2003, 42, 6265-6273.

(62) Pinar, A. B.; Gomez-Hortiguela, L.; Perez-Pariente, J. Chem. Mater. 2007, 19, 5617-5626.

(63) Norby, P. J. Am. Chem. Soc. 1997, 119, 5215-5221.

(64) Yan, W. F.; Song, X. W.; Xu, R. R. Microporous Mesoporous Mater. 2009, 123, 50-62. 